\title{
Influence of Access to Quality Services on Performance of Family Planning Programs in Kuresoi North Sub-County, Nakuru County, Kenya
}

\author{
Jenifer Wothaya Wambugu, Dorothy Ndunge Kyalo, John Mbugua, and Regina Mutave
}

\begin{abstract}
This study investigated access to quality services influence on performance of family planning program in Kuresoi North Sub-County, Nakuru County, Kenya. The study was founded on the theory of constraint and adopted a pragmatism paradigm. It applied descriptive research method using mixed method approach to investigate the influence of access to quality services on performance of family planning program in Kuresoi North Sub-County, Nakuru County, Kenya. The target population in the study was women of reproductive age in 33,482 households distributed in the four Wards of Kuresoi North Sub-County and 19 health management leaders in-charge of all government health facilities offering family planning services in the Sub-County. A sample size of 400 of women of reproductive age and 19 nursing officers in-charge of government health facilities was utilized. The data collection tools used were questionnaire, interview guide, and observation checklist for women of reproductive age and the interview guide for the health facility managers. The research study adopted stratified sampling method. Qualitative data was analyzed according to themes and patterns, and then summarizing the data and linking it to objectives and hypothesis. The study findings exhibited that there was a significant and strong positive individual correlation between access to quality services and performance of family planning program in Kuresoi North SubCounty. The study findings also displayed that there is a significant positive relationship between access to quality services and performance of family planning program in Kuresoi North Sub-County and it predicted the performance of family planning programmes. in Kuresoi North Sub-County.
\end{abstract}

Index Terms-access to quality services, family planning program, reproductive age.

\section{INTRODUCTION}

Family planning programs make a key starring role in prevention of maternal and infant mortality. Despite the benefits associated with family planning, many women continue to encounter unattained family planning needs leading to unwanted pregnancies and compromised health for women and children. A report by [1] indicated that globally, two hundred and fourteen million females of procreative age from underdeveloped nations would like to use a family planning method for child spacing but continue to face challenges and barriers to accessibility.

A quality family planning service should ensure adherence, persistent, and positive referral of individual users as well as contribute to the overall improvement of

Published on June 1, 2020.

Authors are with the University of Nairobi, Kenya.

(corresponding e-mail: wothayaj@yahoo.com) health indicators especially maternal as well as neonatal health [2].

Efficiency is a performance of family planning program dimension which entails offering health care amenities in a technique that it is able to maximize the limited resource use and avoiding wastage. Accessibility is yet another performance of family planning program aspect, which comprises of offering health services that are opportune, physically reasonable, and offered in an atmosphere where knowledge, capacities and resources are suitable to health necessity and client counseling. Another performance of family planning program dimension identified was patientcentered which entails offering health care services, which considers individual or client predilections and goals, and the cultural setup of their societies. Another aspect is unbiassed, which is providing health care services that do not discriminate a person due to individual features like sex, race, culture, topographical setting, or financial standing. In addition, safety was considered as a performance of family planning program aspect. It entails providing health care services, which lessens jeopardies and damage to service consumers.

Achievement in programs related to family planning has been associated with key benefits to countries and the population. The major benefits as described by [1] are; averting pregnancy-linked health dangers in women, dropping new-born mortality, supporting to avert HIV/AIDS, empowering individuals and improving education, as well as dropping adolescent pregnancies and decelerating population advance. Performance of programs related to contraceptives remains significant in attaining the United Nations Sustainable Development Goals. USAID through knowledge for health program revealed that there exists a gap in implementation of family planning worldwide.

Kenya made a great milestone in addressing quality in health by launching Kenya Quality Model of Health $(\mathrm{KQMH})$ care by [3], which provided a conceptual framework for offering holistic and scientific services through addressing a variety of structural quality matters with the key purpose of delivering health effects that are positive.

Access to quality services in family planning entails providing family planning services that are opportune, geographically sensible, and offered within an atmosphere where capacities and resources are suitable to health necessity. It comprises of location of the contraceptives service delivery points, opportune delivery of 
contraceptives services, and family planning counseling room. A good family planning room is important to ensure that clients access the services without barriers such as fear hence ensuring accessibility of the services. Some countries have ensured family planning rooms are well equipped, located in a friendly environment as a way of increasing accessibility.

Ninety-eight percent of health centers examined in Nepal were offering up-to-date contraceptives such as the oral pill, injectable contraceptives, long acting and reversible contraceptives; implants, IUCD, and also both male and female condoms and permanent family planning (voluntary sterilization). The study further outlined that hospitals categorized as zonal that provided contraceptive services on daily basis were only $83 \%$ while those categorized as district hospitals were at $76 \%$, and the private sector at a lower level of $96 \%$. Quality counseling dimension in family planning program means offering family planning services through an interpersonal relationship that help a client to make an informed decision as well as taking into consideration clients or individuals' favorite services and goals and the beliefs of their societies [4].

Access to quality service comprises of components such as client satisfaction, client choice, as well as counseling. Family planning counseling has been outlined by WHO to have six fundamentals which are; Greet consumers, Ask consumers what brought them to the health facility, Tell them about Contraceptive options, Help them to choose a contraceptive that fit them, Explain and demonstrate to a client how to use a the contraceptive methods he/she chooses, how it works, and give a Return or referee the client for addition reviews. The fundamentals are described by an acronym referred to as "GATHER". Patient health care provider interface implies to the interactive conversations amongst a patient receiving knowledge and services in a health care facility or outreach providers for health care offering the essential services.

Despite the launch of the KQMH care document, there is no study conducted on the implementation of KQMH and the influence on performance of family planning program in Nakuru County. Family planning services are very critical services in preventive health especially at primary health care level. This study has utilized the healthcare quality dimensions of access to quality services in relation to performance of family planning program in Nakuru County, focusing on Kuresoi North Sub-County.

The remaining part of this paper is arranged as follows. Section two discusses about literature reviews. Section three deals with data and research methodology. The last two sections focus on empirical analysis and conclusions respectively.

\section{LITERATURE REVIEW}

This study sought to determine the influence of access to quality services on performance of family planning program in Kuresoi North Sub-County, Nakuru County, Kenya. Access to excellence wellbeing care to susceptible populations is a strategy that need to be embraced by many programs. This is in convergence with a study carried out by [5] in America that indicated that the direction to advance the health care of all clients and all societies is to have a clear guideline. In line with this, American Hospital Association developed a path forward, with an obligation in five areas of quality health care which are; access, value, partners, well-being, and coordination. These components are key to achieving quality of health care.

As a way of accessing quality health care, scholars have established ways of clients and patients assessing health services without a physical contact to a clinician. Such innovate ways include the utilization of Telemedicine, which is described by [6] as the utilization of innovation through technology to give wellbeing services from far. The use of telemedicine is suggested to expand access for patients. This would be very helpful to clients who may not need a physical contact with a doctor and will improve health outcomes while reducing medical costs. The use of technology can also reduce many barriers and support good collaboration with patients as well as client owning and taking charge of their health.

An evaluation of 63 studies was done by [7]. The results indicated programmatic gaps and recommended restructuring of family planning programs to target the population irrespective of area of residence and age as way of enhancing accessibility.

Most of the service delivery programs working on family planning have not been keen in reviewing accessibility of family planning in at various ages. In a study carried out in Uganda by [8] indicated that various groups within the population experience different challenges while trying to access contraceptives. These groups included young people and men who continue to face challenges in accessing information related to family planning as well as accessing family planning commodities.

Unattained requirement for contraceptives has been associated with lack of access. Geographical accessibility has remained a major hindrance especially amongst females in rural areas. This is in convergence with a report by [9] that indicated that married men in rural areas had higher unattained need for family planning (30\%) compared to married females in urban areas $(23 \%)$. It was also noted that there was a strong relationship between increased level of unattained requirement for contraceptives and the wealth status. It was noted that as wealth increases, the unattained need for family planning reduces.

Many studies have been conducted to assess the contribution that partners' engagement can bring in female decision making on reproductive health. A research by [10] acknowledged that male engagement can upsurge the access gained in reproductive health services especially contraceptives. The research recommended male participation in all stages of life in order to embrace reproductive well-being of their partners as part of them. This would call for a change in programming to have men targeted messages. This is in convergence with a study by [11] who noted a gap in family planning programming, researchering, as well as in development of policy guidelines. The gap was lack of targeted strategy for male 
involvement. The recommendation was to have men targeted approaches from family planning, preconception, pregnancy and childbirth as well as childcare.

A family planning examination room is important in determining whether clients would take up family planning services as described by [12], who conducted a study on contraceptives services that sought to investigate quality as an element of usage of IUCD in Egypt. The study established that excellence of contraceptive amenities in relationship to counselling and assessment room had robust positive impact on uptake of IUD. Considering the sensitivity of IUD insertion procedure, privacy in examination rooms should be considered in any facility offering family planning services. The indicators for access to quality services in this study will be location, waiting time, counselling room, and services or provider.

Access to harmless, reasonably priced, and quality vital medications and technologies remains a contest in many African countries. In the Universal Health Coverage framework for Africa by [13] indicated access as a pillar to the universal health coverage. The framework further describes the main barriers to accessing quality health care, which included high fees, insufficient funding, frail pharmacological guidelines, insufficient purchasing, and supply systems.

The framework also indicated that most Africa countries had limited access to information regarding health by the general population as well as unsuitable use of information. Africa region has also faced a major challenge in health product with a notable increase of substandard health products as a result of poor performance in enforcing the rules and regulations. Poor health quality access comprises of the cost of care, wastes, and scarce resources. Access to health care ought to accommodate the needs of the entire population. This includes persons living with disability as indicated by a study by [14] that there was need to have a clear definition of people with disability and have it as an access indicator in health care and part of standards.

Access to health care services may have different context and challenges. In an attempt to understand access context in providing maternal health care, [15] evaluated access as in maternal facilities in Bangladesh and Uganda and indicated that health results are dependent on having structures to empower women undergoing health crises to reach suitable health facilities for the services they need. The study observed that the two countries had similar challenges of low utilization of maternal health services which included skilled birth attendance and explicit homegrown structures. The community was also indicated to influence accessibility due to perceptions of acceptable risk and of what constitutes appropriate care.

This is in convergence with a World Health Organization [WHO] report that indicates the status of unattained contraceptive needs amongst females of procreative age. Many clients in the world have unmet family planning requirements owing to numerous justifications like access to the contraceptive amenities. The finding of the research gave more understandings into the decision-making procedures and overwhelming access barricades. Partners were considered to be predominantly significant in Uganda, though, in Bangladesh, various features were found to determine care-seeking which included unqualified resident healers as well as traditional birth attendants. In the two countries, charge and transport barricades were being overcome through use of social networks.

Internationally, about 214 million females of childbearing era from evolving countries wish to have a family planning method but have no access to the contraceptives. Further, Africa was leading with the number of females with unsatisfied contraceptive requirements of $24.2 \%$. Some of the continents which had high contraceptive acceptance included Asia, Latin America and Caribbean which had $10.2 \%$ and $10.7 \%$, levels of unmet family planning requirements [1]. There is need for nations across the globe ton have a strategic plan aimed at addressing the access to quality dimension of family planning.

To improve access, many family planning programs have tried different strategies of implementing family planning. Knowledge for health, which is a USAID program, introduced a Communal-Based Access to Injectable Contraceptives Toolkit as a platform for enhancing the ability of organizations in the designing, operationalising monitoring, evaluating, and rolling out of community-based family planning programs. As well as a tool for to advocacy for changes to national policy and service delivery guidelines in family planning to include the community deports and delivery points. The use of community-based volunteers equally instead of trained nurses to offer family planning occurs [16].

Access can be divided into several components' poverty being a key component as describe by [17] in the study on abject poverty in relation to gaining access to wellbeing services among the growing countries split access into Geographic access and Financial Accessibility. The geographic access described the distance a client travels to seek health services as a significant obstacle to gaining access to health services since there exist a relationship between mileage to healthcare facilities and usage of wellbeing services. Geographical accessibility included the infrastructure since good roads supports the supply of various medical commodities to health facilities as well as appropriate referral mechanisms in case of emergencies. Good in fracture equally promotes mentorship and support supervision for health care workers. Communication is also part of geographical access since lack or inadequate also limits access to health care. Financial Accessibility entails the funding mechanism in the care, which ensures availability of commodities and supplies as well as the cost of health care services since affordability has remained a major barrier in accessing health care.

This is in convergence with a WHO report that indicated that every individual irrespective of gender, age, and race has a right to all health components hence accessibility of health should be guaranteed to all. The report described the need of to have health services accessible, friendly, satisfactory and of great quality. The fact sheet further stated that the health facilities should not just be present but should be functional and offering standard services. In 
addition, it described that accessibility is not just physically accessibility but also financial and the right to pursue, obtain and convey wellbeing-associated knowledge in a reachable set-up [1].

The outcomes of the study were convergent with result of a valuation of contraceptive services carried out in the republic of Kenya. The evidence from Kenya Service Provision evaluation study by the ministry of health Kenya in 2009, which indicated that health centres, clinics, and dispensaries needed to be refurbished to suitable values to support all rudimentary fundamentals of service delivery related to family planning. This was in convergence with findings of a study that indicated that family planning room should have all the equipment's necessary to offer all the family planning including the documentation and reporting tools.

Health financing is one of the biggest components in any country since it indicated the government commitment to supporting health. The USAID, which has been a major donor in financing health programs, envisions a situation where countries would take care of their health status this is well which is outlined in the USAID vision for Health systems strengthening, 2015-2019. In the document, the key to accessing health care services was financial protection, which entailed the cost of accessing quality, wellbeing essential services which normally affect the utilization of the essential services related to health. USAID indicated that accessibility go beyond a service to include greatexcellence, life expectancy-conserving, restraint, advancement, medication, and all services related to care for communities hence the role of health care at community and at health facility level.

Research has also indicated that acceptance of reproductive and sexual health services can be associated with better health results. A study by [18] showed that some better health results can be experienced as a result of utilization of reproductive health services. These indicators include pregnancy outcome, delivery outcome, perinatal, and newborn mortality, maternal illness and deaths as well as spread conditions from mother to child such as HIV/AIDS. The study further highlighted the importance of improving access for contraceptive services to targeted groups such as young people. It further recommended different models for different target populations.

Distance to the health care facility contributes to accessibility of services. A research by [19] in Kenya showed that an increase in distance contributed to a decrease in accessibility of reproductive health services. The report of the study showed that an increment in every one-kilometer lead to a $34 \%$ decreased in accessing services. It is therefore important for health programmers to ensure that no woman travels more than 3 Kilometers to access reproductive health amenities. This would facilitate achievement of Universal Health Care (UHC).

Health departments globally have increased efforts in reducing neonatal mortality and morbidity. These efforts include several strategies such as prevention of unwanted pregnancies especially teenage pregnancies as described by [20], who recognized the role of family planning in reduction of infant mortality. Women need to live within proximity to a health facility to be attended to incase of any emergency. This calls for health departments to advocate for family planning until women are ready to carry a pregnancy and improve distance to health care facilities.

Additionally, accessing reproductive health services among the youths has been a challenge globally. Despite the fact that nations have seen the reality of unattained requirement for family planning, not much efforts have been done to establish strategies of reaching young people with family planning services. Some programs continue to be hindered by the fact that teenagers are not of age and hence parents have to give consent, yet the teenagers are sexually active. This barrier is experienced in many countries, which face a dilemma on offering teenagers family planning commodities [21].

Access to quality service in health care has been broadened to include other components, which are client led. This was discussed in study by [22], which indicated that access goes beyond topographical and monetary access, to the real requirement for services from the client. Client enablement to take lead in his or her health can be considered a significant component in access dimension hence advocacy is key to achieving accessibility. This is in convergence with another study carried out in Canada with an intention of addressing the access barrier to health care, clients were engaged, and they reported harassment by nurses, anxiety, humiliation, and absence of social understanding as the main causes of access barrier. The study recommended the need to urgently address the issues surrounding culturally suitable services [23].

Access to quality service in quality health care has been defined in various context by different scholars [24], defined access to quality service as the ability to have a chance to acquire and suitably use quality health care services. The study equally defined it as the "degree of fit" or compatibility amongst the health structure on one hand and client acceptance to use the services on the other hand. It was therefore divided into various dimensions, which included the availability (geographical access), cost effectiveness (economic access) and suitability (social access) to services related to health.

The study further well-defined excellence in health as well described by Institute of Medicine (IOM) which defines it as the grade at which services related to health care for persons and populaces upsurge the probability of anticipated results in health and that they are dependable beside present specialized information. In addition, the IOM further indicates that excellence essential in health should be efficient, cost-effective, equitable, client centred, safe and timely.

Many countries and continents have developed strategic plan with an aim of addressing the health care quality. One of such initiatives is the European Patient Forum Strategic plan 2014- 2020, which aimed at giving direction in health care. The strategic plan defined accessible health care from the clients' perception, as that health service is available all through in the periods of provision of care, starting with protection normally referred to as promotion of health care 
as well as initial analysis all the way to treatments, comprising of non-therapeutic provision. The strategic plan further stated that topographical situations ought not to bring obstacles in accessing health related care amenities as well as access to knowledge. Access to the right knowledge is a component of quality that needs to be taken into account in health care.

A unique method that was determined to have potential in lessening unattained requirement is through campaigning on partner engagement in contraceptive acceptance [25]. The recommendation made was to have men targeted messaging to advocate for their involvement with a view that if men were made to understand the significance of child spacing, they would support their partners. It was also discovered that most information related to reproductive health only target women and hence need to ensure men have access to health messaging.

In summary, many nations are working towards addressing access to quality family planning services. According to a strategy developed by [26], this was to be realized through improving access across all ages especially among the teens aged between 10-24 as well as increasing access in rural areas and amongst the less privileged populaces. The strategy recommended that to achieve access, there is need to stimulate and advocate transformation of social behaviours among individuals, families, and society. This would help in addressing traditions, misapprehensions, and undesirable consequences and increase utilization of contraceptive use in prevention of unintentional gestations.

\section{DATA AND RESEARCH METHODOLOGY}

This section profiles the research procedures that were applied to address the research objective. These included research model, research strategy, target populace, sample size, and sampling methods, research tools, data gathering methods, data analysis systems, ethical attention and operational description of variables. It also describes the procedures undertaken to guarantee the validity as well as the reliability of the investigation instruments. The section equally includes the ethical concerns. The section concludes with the description of variables.

\section{A. Research Paradigm}

This study was steered by pragmatisms paradigm since the study integrated quantitative and qualitative research strategies by use of mixed technique of data collection and examination. The fundamental hypothesis of the mixed study methodology is that blending numerical and nonnumerical techniques offers a comprehensive knowledge of the investigation problem compared to applying only single kind of techniques as described by [27] and [28]. This is in concurrence with discoveries from a study by [29] who described dual case studies that utilized mixed study approaches and revealed that use of mixed study delivered both quantitative as well as qualitative perceptive which resulted to superlative data elucidation as well as the superlative understanding of the investigation phenomena.
Mixed approaches research provided additional thoughtful of the multifaceted phenomena that was likely to otherwise not be available through using single method only as described by [30]. Pragmatism paradigm was carefully chosen as the most appropriate for this survey since the survey aimed to examine the influence of healthcare quality dimensions and client characteristics on performance of family planning program in Kuresoi North Sub-County, Nakuru County, Kenya.

The choice of the paradigm was to accommodate the diverse approaches of data gathering as indicated by [31] that pragmatism is predominantly suitable for mixed methods. In addition, pragmatism permitted the investigator to be free of psychological and hands-on constrictions executed by the "involuntary optimal contradiction amid post positivism and constructivism as described by [30]. It also enabled the investigator to be independent hence not obliged to a certain research method or technique as stated by [32].

\section{B. Research Design}

The study utilized the descriptive survey using mixed techniques research design. Mixed method is a procedure for steering research that encompasses gathering, scrutinizing and assimilating quantifiable statistics such as surveys and qualitative statistics such as interviews and observation guide as described by [30]. The choice of mixed method was to offer a better consideration of the research problem. The method was selected considering that there had not been a study in Kuresoi North Sub-County testing the effect of management competence on any health program especially family planning. It was of paramount important to therefore use a method that would enable the investigator to continuously review the research question from diverse angles and elucidate unforeseen discoveries and/or probable contradictions.

Use of mixed method approach gave advantage to the study as described by [33] whereby, through use of the approach, the investigator was able to examine uniformity of outcomes obtained by various tools which included; household survey, interview guide, and observation checklist. It also offered data complementation by using both numerical and non-numerical statistics to evaluate overlapping but distinctive aspects of the research phenomenon.

\section{Target Population}

The target population in this study was 33,482 households in Kuresoi North Sub-County, Nakuru County. This number of households in Kuresoi North Sub-County was drawn from the Kenya health information system. The study also targeted the 19 nursing officers in-charge of all government health care facilities offering contraceptive services in Kuresoi North Sub-County.

This target population was useful in providing the required data in the topic under investigation, which was access to quality services and performance of family planning program in Kuresoi North Sub-County, Nakuru County, Kenya. The target population of 33,482 households was guided by the households mapped in Kuresoi North 
Sub-County as per the 2009 Census and 4\% estimated annual population growth as tabulated in the Kenya health information system 2019. The women of procreative age in Kuresoi North Sub-County was equally guided by 2019 Population Estimates revised for Kuresoi North Sub-County as populated in the Kenya Health Information system developed in 2019. This estimate of population and households is usually calculated guided by the population as per the census and the annual growth rate per Sub-County in relation to the proportion of each age cohort. Kuresoi North Sub-County has an estimated growth rate of $4 \%$ per year.

The health care facility in-charges comprised of all 19 officers of government health care facilities in Kuresoi North Sub-County. The women of procreative age were reached at the household level by trained community health volunteers. The estimated number of households in Kuresoi Sub-County were 33,482 which accounts $19.2 \%$ of the total population distributed in the four wards of the Sub-County. The inclusion of the health facility managers in this study was to enhance an understanding on access to quality services and performance of the family planning program.

The inclusion criterion for women of procreative age was the women within the procreative age cohort in a household that were eligible for collecting data from. The exclusion criteria were women of non-procreative age as per the operational definition irrespective of utilizing family planning services. The inclusion criteria for health care facility in-charges was only the nursing officers in-charge of all the government health facilities in Kuresoi North offering family planning services while the exclusion criteria were private health care facility nursing officers incharge irrespective of offering family planning.

\section{Sample and Sampling Procedures}

Sample scope that was utilized for the survey was taken by applying Slovin's method designated by the populace size and the standard allowance error of 0.05 as specified in the equation below.

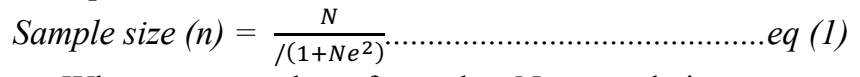

Where; $\mathrm{n}=$ number of samples, $\mathrm{N}=$ population scope, $\mathrm{e}$ $=$ margin of index or error margin. The error margin employed in the study was $5 \%$ as the confidence interval utilized for social sciences is $95 \%$ and the consequent error margin is $5 \%$. Hence, the sample size obtained for the study was 400 respondents.

The sample was allocated in the four wards using the fisheries method for stratified random sampling procedure. The purpose of this method was to maximize sample survey precision from the calculated sample size. This is enumerated in Table I.

The population which was being investigation was homogenous, the study adopted stratified random sampling technique. The definition is in convergence with description by [34] who defined stratified random sampling as a process by which populace is segregated into subcategories known as "strata". Out of which every stratum, the same random sampling is applied in choosing for each-stratum sample. The overall each-stratum samples are thereafter joined to come up with the stratified random sample. It encompassed dividing the populace into standardised subdivisions and then getting a simple random sample in each subcategory.

TABLE I: SAMPLING FRAME

\begin{tabular}{|c|c|}
\hline $\mathbf{N}$ & $\begin{array}{l}\text { Number of stratum (SU1) in the } \\
\text { population }\end{array}$ \\
\hline $\mathrm{M}_{\mathrm{i}}$ & $\begin{array}{l}\text { Total of components (SU2) in stratum } \\
(\mathrm{SU} 1) \mathrm{i}\end{array}$ \\
\hline$M_{O}=\sum_{j=1}^{N} M_{j}$ & $\begin{array}{l}\text { Aggregate number of components (SU2) } \\
\text { in the populace }\end{array}$ \\
\hline $\bar{M}=\frac{M_{O}}{M}$ & $\begin{array}{l}\text { Mean number of components (SU2) for } \\
\text { every stratum (SU1). }\end{array}$ \\
\hline$Y_{i j}$ & $\begin{array}{l}\text { Value of the selected trait of } \\
\text { component (SU2) } \mathrm{j} \text { in stratum (SU1) } \mathrm{i}\end{array}$ \\
\hline$Y_{j}=\sum_{j=1}^{M_{j}} Y_{i j}$ & $\begin{array}{l}\text { Aggregate value of the preferred attribute } \\
\text { in stratum (SU1) } i\end{array}$ \\
\hline $\bar{Y}_{j}=\frac{Y_{j}}{M_{j}}$ & $\begin{array}{l}\text { Mean value of the distinctive } \mathrm{Y} \text { in the } \\
\text { components (SU2) of stratum (SU1) } \mathrm{i}\end{array}$ \\
\hline$Y=\sum_{j=1}^{N} Y_{j}$ & $\begin{array}{l}\text { Aggregate value of the distinctive } \mathrm{Y} \text { in } \\
\text { the populace }\end{array}$ \\
\hline $\bar{Y}=\frac{Y}{N}$ & $\begin{array}{l}\text { Mean value of the distinctive Y for every } \\
\text { stratum (SU1) }\end{array}$ \\
\hline$\overline{\bar{Y}}=\frac{Y}{M_{O}}=\frac{Y}{N \bar{M}}=\frac{\bar{Y}}{\bar{M}}$ & $\begin{array}{l}\text { Mean value of the trait } \mathrm{Y} \text { for every } \\
\text { component (SU2) }\end{array}$ \\
\hline$\overline{\bar{\gamma}}=\sum_{j=1}^{N} \frac{\bar{\gamma}_{j}}{\bar{N}}$ & $\begin{array}{l}\text { Mean value of the feature } \mathrm{Y} \text { for every } \\
\text { component (SU2) if } \mathrm{Mi}=\text { constant }=\mathrm{M}\end{array}$ \\
\hline
\end{tabular}

\section{E. Data Collection Procedures}

The research assistants were guided by the Ward administrator, community health volunteer, the area chief, area assistant chief, and the village elder to identify a central point in each Ward, which was to be the initial point for sampling the households in each ward. The ward was further dived into four routes which informed the starting point. Each direction or route had equal number of questionnaires per the ward. To determine the starting point of data collection, the research assistant rolled a pen on the ground. The direction the sharp edge pointed was the initial route used to commence data collection. The research assistants further visited the first household and then skipped two households and visited every third household in the selected direction. 
The research assistants ensured that they always started from the central starting point in the four routes selected. Upon getting to the household, the research assistants introduced her/himself, sought to know if the household had a woman of reproductive age, and if present, and sought permission from the household head or equivalent to administer the household questionnaire with assurance of confidentiality. For the households that did not have a woman of childbearing age, the research assistant moved to next household without skipping then continued with the pattern of skipping two households.

This study utilized a household questionnaire, key informant interview guide, and observation checklist for data collection. The survey tool for women of procreative age in the designate wards was a questionnaire. The key informant interview guide was utilized among the incharges of health care facilities. Observation checklist was utilized to assess the nineteen health care facilities in Kuresoi North Sub-County. The choice of these instruments was directed by the type of data to be gathered, the dimensions and distribution of the population and also the goal of the research. The use of questionnaire in this study was carefully chosen since it allowed the questioner to gather a more deep and comprehensive information since the interviewer could self-control the procedure henceforth searching additional by adding questions that aided to add additional information dissimilar in an observation method

The questionnaire and interview guide were tested in Molo Sub-County, Nakuru County, Kenya. The pilot test targeted 15 women of procreative age. The choice of Molo Sub-County in Nakuru county was because it was not a study site. The two health facilities were randomly selected in Molo sub-county. The process of piloting was aimed at identifying whether women of reproductive age would understand the interrogations and instructions as well as whether the substance of questions was the similar for all respondents. For the household questionnaire, which had closed ended questions, piloting helped to check the sufficiency of response in the categories that were available. The responses from the participants was also expected to reveal presence of any inconsistencies in the questions within the questionnaire and ability of respondent to respond to all questions. The pilot study gave proper guidance on the tools. The tool collected the data which was intended hence they was no need of revising the tools.

\section{F. Research Instruments Validity and Reliability}

Inferences around the uses of the research apparatuses or instruments was validated. The validation was carried out to ensure that the research instruments had a suitable inference relevant to the purpose of the study and that the research instrument had a meaningful inference hence giving meaningful information using the instrument. The research instrument was tested to divulge the three categories of validity, which were; content-interrelated indication of validity, the criterion-interrelated indication of validity and the construct interrelated indication of validity. Utilization of experts in the area of reproductive health was done to help in assessing the subject matter validity. The tool was reviewed by the county health management team for any error. A small team that comprised of County Director of Strategic Planning, County Director of Quality Assurance and County reproductive health coordinator were tasked to review and give feedback on content. The review was followed by a presentation to the county health management team and later permit to collect data was given. The researcher put into consideration sentiments of raised by the Nakuru County Health Management Committee.

To ensure reliability of the research tools, they were exposed to testing to guarantee that the features of steadiness and equivalency were certain. The method used to measure reliability of the study tools was test re-test method. The interview guide was tested in two health facilities in Molo Sub-County targeting health facility incharges while the questionnaire for the women of procreative age was tested in Kuresoi North Sub-County interviewing 20 women of procreative age at house level. The women of procreative age were visited in their respective households, explained to about the survey and upon giving consent, they were interviewed. They were given an appointment of one month when the researcher returned to the same households and interviewed the same women using the same questionnaire. The two-health facilities in-charge were interviewed utilizing the interview manual and the given an appointment of one month after which the same interview manual was utilized to interview them. The results of the two sets of were calculated for correlation using SPSS.

\section{G. Data Analysis Techniques}

This survey produced both quantitative and qualitative data to describe the influence of access to quality services on performance of family planning program. The filled questionnaires were obtained, coded, and edited for comprehensiveness and steadiness. The data was examined by applying descriptive and inferential statistics using the Statistical Package for Social Science (SPSS). This was utilized to give both descriptive and inferential statistics which enhanced examination of the hypothesis at the significance level of 0.05 and the confidence interval of $95 \%$.

Qualitative data was analyzed from the in-depth interviews and observation checklist and involved analyzing transcripts and identifying themes within that data. This also involved putting together themes that were alike from the text thus qualitative data was analyzed by checking data, developing codes, identifying themes and patterns, and then summarizing the data and linking them to objectives and hypothesis.

A simple linear regression analysis was carried out to analyze the influence of access to quality services on the performance of family planning program. The hypothesis was also analyzed using Pearson's Product Moment Correlation for interpretation of results. Correlation analysis was key in order to determine the association between the independent and dependent variables. Finally, the data was analyzed descriptive statistics for the quantitative analysis of data. The data was then be presented using frequency distribution tables for easier understanding. 


\section{EMPIRICAL ANALYSIS}

The empirical analysis section contains four parts which include, descriptive statistics, content analysis, observation chart, correlation analysis, simple linear regression analysis, and discussion of empirical findings.

\section{A. Descriptive Statistics}

The study sought to determine the mean, standard error and standard deviation of access to quality services. This was analyzed using SPSS. There were ten questions distributed among the four indicators of the independent variable (access to quality services). The mean, standard error and standard deviation was analyzed as per as the results in the in Table II below.

TABLE II: MANAGEMENT COMPETENCY DESCRIPTIVE

\begin{tabular}{lllll}
\multicolumn{5}{c}{ STATISTICS } \\
\hline & $\begin{array}{l}\text { N } \\
\text { Statistic }\end{array}$ & $\begin{array}{l}\text { Mean } \\
\text { Statistic }\end{array}$ & Std. Error & $\begin{array}{l}\text { Std. Deviation } \\
\text { Statistic }\end{array}$ \\
\hline Access Dimension & 400 & 33.81 & .359 & 7.177 \\
\hline Valid N (listwise) & 400 & & & \\
\hline
\end{tabular}

The results exhibit a mean of 33.81, standard error of 0.359 , and standard deviation of 7.177. Interpretation: About $68 \%$ of the sample population (assuming a normal distribution) at one standard deviation is between (33.81 $0.359)=33.441$ and $(33.81+0.359)=34.169$, which has an average of 33.805 . This indicated that the sample population tended to be neutral on access to quality dimension in the health facilities they were seeking family planning services. The views of the sample population gave the same views with the total population, which was between $33.81-7.177=26.633$ and $33.81+7.177=40.987$ with average of 33.81 .

The study also sought to measure the mean and standard deviation of performance of family planning program. Table III shows the results.

TABLE III: PERFORMANCE OF FAMILY PLANNING PROGRAM

\begin{tabular}{|c|c|c|c|c|c|}
\hline \multicolumn{6}{|c|}{ DESCRIPTIVE STATISTICS } \\
\hline & & $\mathbf{N}$ & Mean & & Std. \\
\hline & & Statistic & Statistic & $\begin{array}{l}\text { Std. } \\
\text { Error }\end{array}$ & Statistic \\
\hline Performance & & 400 & 36.43 & .368 & 7.357 \\
\hline $\begin{array}{l}\text { Valid } \\
\text { (listwise) }\end{array}$ & $\mathrm{N}$ & 400 & & & \\
\hline
\end{tabular}

The results display a mean of 36.43 , SE of 0.368 and SD of 7.357. This implies that $68 \%$ of the sample population at one standard deviation is between $(36.43-0.368)=36.0621$ and $(36.43+0.368)=36.798$, which has an average of 36.43. This indicated that the sample population tended to agree on the performance of family planning program. The views of the sample population gave the same views with the total population, which was between $36.43-7.357=$ 29.073 and $36.43+7.357=43.787$ with average of 36.43 .

\section{B. Content Analysis}

Content analysis was conducted on questions asked in the interview guide pertaining to access to quality services. The findings are enumerated below. The interview with health care providers explored to establish the schedule of family planning services in the government. $100 \%$ of the nursing officers interviewed indicated that the family planning services were offered on daily basis from Monday to Friday starting at $8.00 \mathrm{am}$. to $5.000 \mathrm{pm}$. It was noted that during the weekend and in the evening the services not offered. The hospitals need to explore offering the services during the weekends and evening in order to enhance uptake among the youth and the working class and encourage adherence to the appointment dates.

Nursing officers were interviewed on how they ensured that the equipments used in family planning were sterilized. $11 \%$ indicated that they did not have an autoclave or electricity hence they were not able to offer methods like IUCD insertion or removal as well as removal of implants. $70 \%$ of the health facilities had autoclave and were able to autoclave when there was need, while $19 \%$ had autoclave but only sterilized equipment once per week. The county department of health needs to ensure that all the health facilities related to electricity had had autoclave to facilitate their functions in enhance family planning coverage.

On the cost of family planning services, $90 \%$ of the nursing officers interviewed indicated that the services were free, while $5 \%$ indicated that client were paying Kenya Shillings (KES) one hundred for family planning. Additionally, 5\% indicated the clients were paying as a per the family planning method chosen. For instance, they paid KES fifty for injectable, KES two hundred for IUCD, and KES fifty for combined oral contraceptives. The Subcounty needs to ensure adequate supplies of commodities and wave all the costs.

On the geographical accessibility, $90 \%$ of the nursing officers interviewed indicated that clients travelled more than $3 \mathrm{KM}$, between $3-6 \mathrm{KM}$, to the heath facility to seek services. 5\% indicated that clients traveled between 2 and 3 $\mathrm{KM}$, while $5 \%$ indicated that clients were traveling for at least $7 \mathrm{KM}$. They recommended use of outreaches and appealed to the county government to establish more health facilities.

On the access to family planning, $100 \%$ of the nursing officers interviewed indicated that they were able to give information to clients on contraceptives use and side effects. They stated that they reached clients at the community level through Community Health Volunteers (CHVs) and through giving health messages during the village briefings. They also gave information to all clients and patients by routine health messages, which are normally carried out every morning. The clients who also attend family planning services, and are given information during one on one counseling with the health care workers.

The nursing officers were also interviewed on other benefits that the clients using family planning services got, in form of extra services. $68 \%$ of the nursing officers indicated that they provided clients with HIV counseling and testing, as well as routine cervical cancer screening and couple counseling. $15 \%$ indicated that clients got other outpatient services such as treatment of minor illness, while $17 \%$ indicated that clients were able to get health education 
on other related services such as antenatal care, postnatal care, and safe maternity delivery by skilled birth attendant.

Nursing officers were interviewed regarding client's information and how they ensured safety of client confidential information. $36.8 \%$ indicated that all information was indicated in the client's card and clients went home with the cards hence detailed information was not left at the health facility. $63.2 \%$ indicated that client information was only limited to the information collected in the family planning register, which was very limited. However, this indicated that it was very easy to lose the clients data especially retrieving client's history.

A question on whether client was able to get her information upon request was asked, and $100 \%$ of the nursing officers indicated that it was not possible to get clients information. Thus, there is need to have all client's information stored electronically for easy retrieval and use for both the health care workers and the client to aid in monitoring method failure.

\section{Observation Chart}

Nineteen dispensaries and health centers in Kuresoi North Sub-County were investigated on the availability of Tiahrt Charts in the respective dispensaries and health centers. The Tiahrt Charts entail provisions of the Tiahrt amendment, which was enacted in the 1999 Foreign Operations Appropriations Act, which reflects values and principles concerning voluntary family planning projects and informed choice guiding United States Agency for International Development (USAID) family planning assistance. Presence of Tiahrt Charts indicates quality provision of family planning services. Thirteen dispensaries and health centers had Tiahrt Charts while 6 did not. This is clearly illustrated in the Fig 1. 68\% of the dispensaries and health centers had Tiahrt Charts while $32 \%$ did not have.

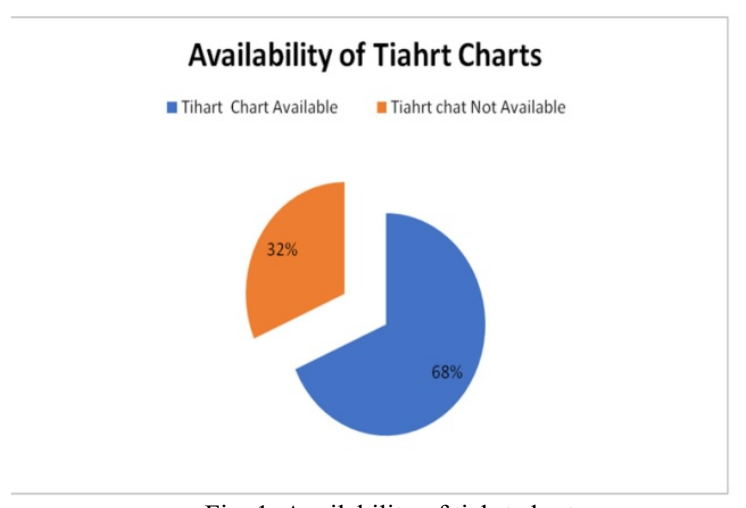

Fig. 1. Availability of tiahrt charts.

The study further investigated whether family planning is integrated in other departments in the 19 dispensaries and health centers. The findings presented that all the 19 dispensaries and health centers integrated family planning in their other departments, translating to $100 \%$ of integration of family planning in various departments.

\section{Correlation Analysis}

The study sought to establish the influence of access to quality services on performance of family planning program in Kuresoi North Sub-County, Nakuru County, Kenya.
Access to quality services as an independent variable was guided by four indicators which were; geographical location, cost of service, availability of services or health care provider and access to information on family planning. Table IV shows the correlation.

The study identified a strong positive correlation of 0.599 between access to quality services and performance of family planning program in Kuresoi North Sub-County and a significance level of 0.00 which is less than the significance level of 0.05 . Thus, there is a significance association between access to quality services and performance of family planning program.

\begin{tabular}{|c|c|c|c|}
\hline & & $\begin{array}{l}\text { Access } \\
\text { Dimension }\end{array}$ & Performance \\
\hline \multirow[t]{3}{*}{ Access Dimension } & Pearson Correlation & 1 & $.599^{* *}$ \\
\hline & Sig. (2-tailed) & & .000 \\
\hline & $\mathrm{N}$ & 400 & 400 \\
\hline \multirow[t]{3}{*}{ Performance } & Pearson Correlation & $.599^{* *}$ & 1 \\
\hline & Sig. (2-tailed) & .000 & \\
\hline & $\mathrm{N}$ & 400 & 400 \\
\hline
\end{tabular}

**. Correlation is significant at the 0.01 level (2-tailed).

\section{E. Simple Linear Regression Analysis}

The study sought to test the fitness of the model on relationships between access to quality services and performance of family planning programs. The study also sought to test hypothesis that there is no significant relationship between access to quality services and performance of family planning program. Finally, the study sought to measure the strength of the relationship between access to quality services and performance of family planning program. Tables $\mathrm{V}$ shows the results of the model.

The results showed that R Square value was 0.358 . Thus, access to quality services predicts $38.9 \%$ of performance of the family planning program in Kuresoi North Sub-County, Nakuru County, Kenya. Consequently, $61.1 \%$ of the deviations in family planning are explained by the other factors not included in the study.

The result also indicated that significance value obtained in the analysis of variance is 0.00 , which is less than the critical of 0.05 . Thus, the null hypothesis that access to quality services does not predict performance of family planning program is rejected. Hence, the model of access to quality services predicting performance is therefore fit.

The result indicated that significance value obtained from the model coefficients is 0.00 which is less than the critical value of 0.05 . Thus, access to quality services significantly affects performance, the null hypothesis that access to quality services does not significantly affect performance of family planning program is rejected.

\begin{tabular}{|c|c|c|c|c|c|c|c|}
\hline \multirow{3}{*}{$\begin{array}{l}\text { Model } \\
1 \\
\text { Model }\end{array}$} & \multirow{2}{*}{$\begin{array}{l}\mathbf{R} \\
.599^{\mathrm{a}}\end{array}$} & \multicolumn{2}{|c|}{$\begin{array}{l}\mathbf{R} \\
\text { Square }\end{array}$} & \multirow{2}{*}{$\begin{array}{l}\begin{array}{l}\text { Adjusted } \\
\text { Square }\end{array} \\
.357\end{array}$} & \multirow[t]{2}{*}{$\mathbf{R}$} & \multicolumn{2}{|c|}{$\begin{array}{l}\text { Std. Error of } \\
\text { the Estimate }\end{array}$} \\
\hline & & .358 & & & & 5.901 & \\
\hline & & $\begin{array}{l}\text { Sum of } \\
\text { Squares }\end{array}$ & & $\begin{array}{l}\text { Mean } \\
\text { Square }\end{array}$ & $\mathbf{F}$ & F & Sig. \\
\hline \multirow[t]{3}{*}{1} & $\begin{array}{l}\text { Regressio } \\
n\end{array}$ & 7737.883 & 1 & 7737.883 & & 222.196 & $.000^{\mathrm{b}}$ \\
\hline & Residual & $\begin{array}{l}13860.15 \\
7\end{array}$ & 398 & 34.825 & & & \\
\hline & Total & 21598.04 & 399 & & & & \\
\hline
\end{tabular}




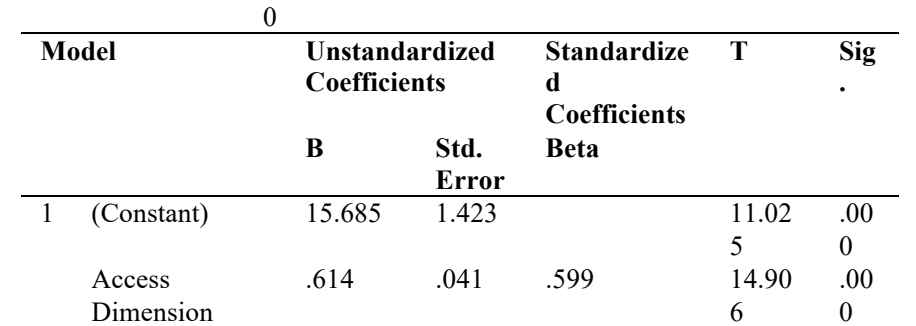

a. Dependent Variable: Performance

b. Predictors: (Constant), Access Dimension

The following model is thus developed;

$Y=15.685+0.614 X \ldots \ldots \ldots \ldots \ldots \ldots \ldots \ldots \ldots \ldots \ldots \ldots . . .12$ eq $(2)$

This implies that when one improves access to quality services by one unit, there is an increase in performance of family planning program by 0.614 units.

\section{F. Discussion of Findings}

The study findings displayed that there was a significant and strong positive correlation between access to quality services and performance of family planning program in Kuresoi North Sub-County. The study findings also exhibited that there is a significant positive relationship between access to quality services and performance of family planning program in Kuresoi North Sub-County. The study further exhibited that access to quality services predicted and described to a large extent the performance of family planning.

The current study findings are in convergence with a study carried out by [5] in America that indicated that the direction to advance the health care of all clients and all societies is to have a clear guideline. The current study findings are congruent to the findings of a study carried out by [6], which established that innovate ways like utilization of Telemedicine, which is the utilization of innovation through technology, provide excellent wellbeing services. The study suggested that use of telemedicine is suggested to expand access for patients and this would be very helpful to clients who may not need a physical contact with a doctor and will improve health outcomes while reducing medical costs. The study opined that use of technology can also reduce many barriers and support good collaboration with patients as well as client owning and taking charge of their health.

In the Universal Health Coverage framework for Africa by [13] indicated access as a pillar to the universal health coverage. This is in agreement with the current study findings. The current study findings are also parallel to the study findings by [15], which established that access to health care services may have different context and challenges. In an attempt to understand access context in providing maternal health care, the study evaluated access as in maternal facilities in Bangladesh and Uganda and indicated that health results are dependent on having structures to empower women undergoing health crises to reach suitable health facilities for the services they need. The community was also indicated to influence accessibility due to perceptions of acceptable risk and of what constitutes appropriate care.

This current study findings are also in convergence a report by [1] that indicates the status of unattained contraceptive needs amongst females of procreative age and many clients in the world have unmet family planning requirements owing to numerous justifications like access to the contraceptive amenities. The findings also outlined that in Bangladesh and Uganda, high charges and transport barriers to access to family planning services were being overcome through use of social networks.

Current study findings are in tandem with the USAID program called Knowledge for Health which introduced a Communal-Based Access to Injectable Contraceptives Toolkit as a platform for enhancing the ability of organizations in the designing, operationalising monitoring, evaluating rolling out of community-based family planning programs as well as a tool for to advocacy for changes to national policy and service delivery guidelines in family planning to include the community deports and delivery points. The program established that the use of communitybased volunteers equally instead of trained nurses to offer family planning will bolster access [16].

The current study findings are in convergence with a research by [12] that focused on excellence component of family planning as a contributing factor in consumption of IUD in Egypt. The research indicated that excellence of services in relationship to counselling and room used to offer the contraceptive services contributed to a strong positive result in the uptake of IUD.

The outcomes of the current study are convergent with a Kenya Service Provision evaluation study by the ministry of health Kenya in 2009, which indicated that health centres, clinics, and dispensaries needed to be refurbished to suitable values to support all rudimentary fundamentals of services delivery related to family planning and that in absence of such essential tools, it is difficult to offer quality services. The current study findings are also in tandem with a study by [35] on a paper from the Bellagio Meeting on dimension in family planning which indicated the necessity to have a checklist on all the necessities in a family planning counselling rooms to ensure and measure quality and that a checklist would act as a good guide to all the health care providers to ensure and maintain quality.

The current study findings are in agreement with those of a study by [18], which exhibited that some better health results can be experienced as a result of utilization of reproductive health services. The study further highlighted the importance of improving access for contraceptive services to targeted groups such as young people. It further recommended different models for different target populations.

The current study finding is also in convergence with another study carried out in Canada by [23] with an intention of addressing the access barrier to health care. The study reported that clients were engaged, and they reported harassment by nurses, anxiety, humiliation, and absence of social understanding as the main causes of access barrier.

Finally, the current study findings are congruent to the findings of a report by IOM, which stated that access to quality dimension in quality health care is the grade at which services related to health care for persons and population upsurge results in the probability of anticipated 
results in health which are dependable beside presenting specialized information. In addition, the IOM further indicates that excellence essential in health should be efficient, cost-effective, equitable, client centred, safe and timely.

\section{CONCLUSIONS}

The study findings concluded that there was a significant and strong positive correlation between access to quality services and performance of family planning program in Kuresoi North Sub-County. The study findings also concluded that there is a significant positive relationship between access to quality .

The study finally concluded that access to quality services predicted and described to a large extent the performance of family planning.

Thus, recommendations can be made to the health regulatory authorities and health facilities to increase access to quality services in order to increase the performance of family planning programs. In order to improve access to quality services, regulatory authorities should set up health facilities in close proximity to the populace in order to minimize the cost and time of accessing family planning services. They should also subsidize family planning services in order to minimize their cost. In order to improve access to quality services, the health facilities should; offer sufficient information on the family planning and make the information accessible and easy to understand, ensure adequate supply of contraceptives and other family planning medication, sensitize the male gender about family planning, and offer family planning services frequently preferably on daily basis during weekdays

The current study conclusions are in convergence with a study carried out by [5] in America that indicated that the direction to advance the health care of all clients and all societies is to have a clear guideline. The current study findings are also congruent to the findings of a study carried out by [6], which established that innovate ways like utilization of Telemedicine, which is the utilization of innovation through technology, provide excellent wellbeing services. The study suggested that use of telemedicine is suggested to expand access for patients and this would be very helpful to clients who may not need a physical contact with a doctor and will improve health outcomes while reducing medical costs. The study opined that use of technology can also reduce many barriers and support good collaboration with patients as well as client owning and taking charge of their health.

\section{REFERENCES}

[1] Family planning/Contraception Key facts, World Health Organization, (2018).

[2] S. Cohen and W. Yu. Rockville, "The Concentration and persistence in the level of health expenditures over time: Estimates for the U.S. population 2009-2010," MD: Agency for Healthcare Research and Quality; Nov, 2012.

[3] Implementation Guideline for Kenya Quality Model of Health $(\mathrm{KQMH})$ Care, Ministry of Medical services and Ministry of Public Health and sanitation, 2012.
[4] Nepal Health Facility Survey: Key Findings, Kathmandu, Nepal, Ministry of Health, Kathmandu; New ERA, Nepal, 2015.

[5] J. Bhatt, and P. Bathija, "Ensuring access to quality health care in vulnerable communities," Academic Medicine: Journal of the Association of American Medical Colleges, vol 93, no 9, pp 12711275, 2018.

[6] H. Daniel, and L. S. Sulmas, "Policy Recommendations to Guide the Use of Telemedicine in Primary Care Settings," for the Health and Public Policy Committee of the American College of Physicians: An American College of Physicians Position Paper, Ann Intern Med, 2015, 163, pp 787-789.

[7] L. Mwaikambo, I. S. Speizer, A. Schurmann, G. Morgan, and F. Fikree, "What works in family planning interventions: A systematic review," Studies in family planning, vol 42, no 2, pp 67-82, 2011.

[8] G. Nalwadda, F. Mirembe, J. Byamugisha, and E. Faxelid, "Persistent high fertility in Uganda: Young people recount obstacles and enabling factors to use of contraceptives," BMC Public Health, 2010, 10, p 530.

[9] Uganda Demographic and Health Survey, Uganda Bureau of Statistics (UBOS) \&ICF, Kampala, Uganda and Rockville, Maryland, USA: UBOS and ICF, 2016.

[10] K. M. Sileo, R. K. Wanyenze, H. Lule, and S. M. Kiene, "That would be good but most men are afraid of coming to the clinic: Men and women's perspectives on strategies to increase male involvement in women's reproductive health services in rural Uganda," Journal of Health Psychology, vol 22, no 12, pp 1552$1562,2017$.

[11] C. C. Okigbo, I. S. Speizer, M. Corroon, and A. Gueye, "Exposure to family planning messages and modern contraceptive use among men in urban Kenya, Nigeria, and Senegal: A cross-sectional study," Reprod Health, vol 12, no 63, 2015.

[12] R. Hong, L. Montana, and V. Mishra, "Family planning services quality as a determinant of use of IUD in Egypt," BMC Health Services Research, vol 6, no 79, 2006.

[13] H. Wang, M. A. Juma, N. Rosemberg, and M. M. Ulisubisya, "Universal health coverage in low-income countries: Tanzania's efforts to overcome barriers to equitable health service access," Universal Health Coverage Studies, World Bank, Washington, DC, $2018,39$.

[14] M. MacLachlan, and H. Mannan, "The world report on disability and its implications for rehabilitation psychology," Rehabilitation Psychology, vol 59, no 2, pp 117-124, 2014.

[15] J. O. Parkhurst, S. A. Rahman, and F. Ssengooba, "Overcoming access barriers for facility-based delivery in low-income settings: insights from Bangladesh and Uganda," Journal of Health, Population, and Nutrition, vol 24, no 4, pp 438-445, 2006.

[16] Applying a Quality Improvement Model to Strengthen Communitybased Family Planning Services in Busia District, Uganda, USAID, 2016, 1.

[17] D. Peters, A. Garg, G. Bloom, D. G. Walker, W. R. Brieger, and M. $\mathrm{H}$. Rahman, "Poverty and access to health care in developing countries," Annals of the New York Academy of Sciences, vol 1136, pp 161-171, 2008.

[18] J. Yao, A. T. Murray, and V. Agadjanian, "A geographical perspective on access to sexual and reproductive health care for women in rural Africa," Social Science and Medicine, vol 96, pp 60-68, 2013

[19] D. R. Feikin, L. M. Nguyen, K. Adazu, M. Ombok, A. Audi, L. Slutsker, A. Kim and A. Lindblade (2009). The impact of distance of residence from a peripheral health facility on paediatric health utilisation in rural western Kenya, https://doi.org/10.1111/j.13653156.2008.02193.

[20] M. Målqvist, N. Sohel, and T. T. Do, "Distance decay in delivery care utilization associated with neonatal mortality. A case referent study in northern Vietnam," BMC Public Health, 2010, 10, p 762.

[21] M. Campbell, "Consumer behavior and contraceptive decisions. Resolving a decades-long puzzle," J Fam Plann Reprod Health Care, vol 32, no 4, pp 241-244, 2006.

[22] R. O'Loughlin, and A. Kelly, "Equity in resource allocation in the Irish health service. A policy Delphi study," Health Policy, vol 67, no 3, pp 271-280, Mar 2004.

[23] B. L. Cameron, M. D. P. C. Plazas, A. S. Salas, and K. Hungler, "Understanding inequalities in access to health care services for aboriginal people," Advances in Nursing Science, Vol. 37, No. 3, pp. E1-E16, 2014.

[24] J. E. Ataguba, J. Akazili, and D. McIntyre, "Socioeconomic-related health inequality in South Africa: Evidence from general household 
surveys, " International Journal for Equity in Health, Vol 10, pp. 48, 2011.

[25] A. Dougherty, A. Kayongo, S. Deans, J. Mundaka, F. Nassali, J. Sewanyana, and R. Kalyesubula, "Knowledge and use of family planning among men in rural Uganda” BMC Public Health, 2018, 18, 1294.

[26] Uganda Family Planning Costed Implementation Plan, 2015-2020, Kampala: Ministry of Health, Uganda, 2014.

[27] J. W. Creswell, Research Design: Qualitative, Quantitative, and Mixed Methods Approaches, 4th ed, 2014.

[28] J. F. Molina-Azorin, "Mixed methods research: An opportunity to improve our studies and our research skills," European Journal of Management and Business Economics, vol 25, pp 37-38, 2016.

[29] A. Mitchell, "A review of the mixed methods, pragmatism and abduction techniques," The Electronic Journal of Business Research Methods, vol 16, pp 103-116, 2018.

[30] J. W. Creswell, and V. L Plano-Clark, Designing and Conducting Mixed Methods Research,2nd ed., Thousand Oaks, CA: Sage Publications, Inc, 2018.

[31] D. L. Morgan, pragmatism as a paradigm for social research, Qualitative Inquiry, vol 20, no 8, pp 1045-1053, 2014.

[32] C. Robson, Real World Research, Oxford, UK: Blackwell, 1993.

[33] J. Morse, and L. Niehaus, Mixed Method Design: Principles and Procedures, Walnut Creek, CA: Left Coast Press, 2010.

[34] T. D. Nguyen, M. Shih, D. Srivastava, S. Tirthapura, and B. Xu, "Stratified Random Sampling from Streaming and Stored Data," Electrical and Computer Engineering Conference Papers, Posters and Presentations, 2019.

[35] S. H. Leisher, A. Sprockett, K. Longfield, and D. Montagu, "Quality Measurement in Family Planning: Past, Present,Future," Papers from the Bellagio Meeting on Family Planning Quality, Oakland, CA: Metrics for Management, October 2015.

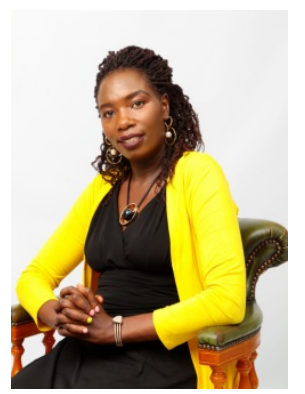

Dr. Wothaya was born in Kenya on $21^{\text {st }}$ September, 1978. She currently resides in Kenya. She graduated with a Bachelor of Science in Nursing degree at Kenya Methodist University, Meru, Kenya in 2014. She was further awarded with a Master's in Project Planning and Management degree at the University of Nairobi Kenya in 2016. She obtained a Doctor of Philosophy in Project Planning and Management degree at the University of Nairobi in 2020.

She currently works as a Program Officer in charge of Management. Organization: Family Health International (FHI360) Kenya. The program is labelled as USAID Afya Uzazi Nakuru/Baringo and is located at Nakuru County, Kenya. From April 2011 to Sept 2017, she worked at Jhpiego Kenya as the Team Lead/Technical Officer in the Reproductive Maternal neonatal Child and Adolescence Health Program. The program is labeled as USAID APHIA PLUS KAMILI and is Located in Kirinyaga and Kitui Counties, Kenya. From May 2004 to March 2011, she worked at the Ministry of Health Kenya as the provincial PMTCT Coordinator in Central Province, Kenya.

Dr. Wothaya is registered with the Nursing Council of Kenya. She was awarded with the 2008 Regional (Central Province) Nurse of the year $4^{\text {th }}$ runners up in the Nation. 